\title{
Attitudes to aging mediate the relationship between older peoples' subjective health and quality of life in 20 countries
}

\author{
Gail Low ${ }^{1 *}$, Anita E Molzahn² and Donald Schopflocher ${ }^{3}$
}

\begin{abstract}
Background: With ever-increasing life expectancy globally, it is imperative to build knowledge of how older peoples' views of their own aging, considering their health-related circumstances, affect quality of life for practitioners and policy-makers alike. Based on our literature review, we wanted to determine whether older adults' attitudes toward their own aging would partly mediate the effect of their health satisfaction ratings upon their quality of life. Furthermore, would these attitudes mediate the relationship between health satisfaction and quality of life in the same way when we account for older adults' country of origin, and their age and gender?
\end{abstract}

Methods: This was a secondary analysis of cross-sectional survey data collected in 20 countries taking part in the 2003 WHOQOL-OLD Field study. The study sample consisted of 4593 adults whom were, on average, 72.10 years of age (range $=60$ to 100 years of age); $42.8 \%$ were female. The WHOQOL-BREF measured quality of life and health satisfaction. The Attitudes to Aging Questionnaire measured participants' attitudes toward physical change, psychosocial loss, and psychological growth. All items in both questionnaires were measured on a 5-point Likert scale. Questionnaire responses were analyzed using multilevel modeling and path analysis.

Results: All three attitudes to aging partly mediated the relationship between health satisfaction and physical, psychological, social, environmental, and global quality of life. These partial mediations manifested in the same way across all 20 country samples, regardless of age or gender. Attitudes toward physical change were the strongest mediator of health satisfaction upon global and domain-specific quality of life, followed by psychosocial loss and psychosocial growth.

Conclusions: Our study is the first cross-cultural study with a large sample to show that quality of life judgements, between 60 to 100 years of age, are a product of older men's and women's perceptions of health-related circumstances, and attitudes toward physical and psychosocial aspects of the aging self. A prospective study of the linkages between older peoples' subjective views of health and attitudes toward the aging self over time using multiple subjective measures of health is warranted. Understanding these linkages may help practitioners and policy makers consider strategies to enhance quality of life.

Keywords: Attitudes to aging, Subjective health, Quality of life, Statistical models

\footnotetext{
* Correspondence: gail.low@ualberta.ca

${ }^{1}$ Faculty of Nursing, University of Alberta, 11405-87 Avenue, Edmonton, AB

T6G 1C9, Canada

Full list of author information is available at the end of the article
} 


\section{Background}

From a developmental perspective, striving for a sense of integrity (versus despair) is one of the hallmark attributes of older adulthood; this is particularly challenging when one's health-related circumstances are less favorable [1]. Poor health can interfere with older peoples' integrity work or ability to accept changes in overall physical function and appearance, come to terms with losses of social roles, and foresee opportunities for growth in an unknown future [2,3]. In the quality of life (QOL) literature, little attention is given to attributes marking older adulthood [4] yet none of us are exempt from the developmental work associated with this life stage [3]. With ever-increasing life expectancy globally, factors affecting older peoples' capacity to live a longer life of quality is a pressing issue $[5,6]$. Hence, it is imperative to build knowledge of how older peoples' views of their own aging, considering their health-related circumstances, affect QOL for practitioners and policy-makers alike. One way to build such knowledge is to examine older peoples' attitudes toward their own aging.

We understand attitudes to be stable integrative judgements that summarize the thoughts, feelings, and memories people have toward objects or situations from their direct experience or observation [7-9]. Attitudes can be formed about important life events [8] and attributes characteristic of those events [9], for example, the developmental stage of older adulthood. Thus, based on their observations of other older people an older person might judge that physical changes are part-and-parcel of getting older and may more positively evaluate their own aging in terms of physical changes. That is, attitudes towards aging may mediate self-reports of physical and psychological states. Across 20 country samples, we investigate how men's and women's attitudes toward their own aging in relation to physical change, psychosocial loss and psychological growth, and perceptions of their healthrelated circumstances affect their QOL between the ages of 60 to 100 .

Various measures of health and functioning have been linked to attitudes to aging among older adults. Subjective perceptions of physical, cognitive and social aging have been found to influence mental health in terms of symptoms of depression, self-esteem and morale [10]. In other studies, age-related morale has explained respiratoryrelated mortality [11], longevity [12], and the capacity for activity in and outside of the home over time [13]. Poor health has had a negative impact on perceptions about old age and of aging in general [14]. Poor health may also influence how old a person feels versus how old they actually are [15]. Feeling older has also been associated with more pessimistic attitudes about aging as it relates to thinking, sharpness, and memory [16]. Being in good health has been found to reduce anticipation of physical and social loss [17], increase the tendency to frame older age as a time of continuous growth, lesser physical decline and social loss [18], and decrease negativity toward the future and physical change, including bodily aging $[19,20]$. Symptoms of depression have negatively affected attitudes toward psychosocial growth [21] as well as age identity, life satisfaction ratings, and affect [22]. Others have related higher ratings of mental and physical functioning to more positive age-related expectations about energy and pain, time with friends and family, and forgetfulness [23]. Being in good to excellent health also appears to be related to higher QOL [24].

Quality of life judgements are a product of the individual's subjective view of illness and his or her view as to how this affects the physical, psychological and social self [25]. In other words, illness might be interpreted by individuals differently as detracting from or contributing to QOL based on their attitudes toward the aging self. In a psychometric study of the WHOQOL-BREF, significant correlations were reported between older peoples' attitudes toward aging (specifically physical change, and psychosocial loss. and psychological growth), and their physical, psychological, social, and environmental QOL ratings [26]. Middle-aged adults' actual (versus perceived) age has been found to predict their beliefs, over time, about the relative QOL in older adulthood compared to younger adulthood [27]. Other findings provide further evidence of a direct link between health and attitudes to aging; specifically, subjective ratings of health have been found to explain self-appraisals of older age through multiple health problems from midlife onward [28] and in older age [29]. Similarly, older people who appraise their health in a positive light have been found to report better age-related morale when one considers their will to live [12] and opportunities to continue achieving in life [13]. Believing that older age is a time of personal development [30] and better age-related morale [31] has been found to mediate the effect of subjective health ratings on life satisfaction. Attitudes toward psychosocial loss have been found to partly mediate the effects of perceived memory, mental status, and capacities for activities of daily living upon the QOL of older adults with dementia [32]. Hence, we hypothesized that older adults' attitudes toward their own aging would mediate, at least in part, the effect of their health satisfaction ratings upon their global, physical, psychological, social, and environmental QOL.

Beliefs about the cultural institutions and norms (as a broad psychological factor) potentially influence how information is used to make QOL judgements [25]. Whether and how subjective views of illness affect aspects of the self could differ based on a person's country of origin. This emphasis on culture is consistent with definitions of QOL as a culturally-sensitive appraisal [33] and of attitudes as part of cultural group membership, in that 
they originate from in-group norms and thus are an expression of one's social identification with the group [34]. Country of origin has been found to influence agerelated morale [35] and subjective age-identity [22] among adults of all ages, and perceptions of older age as a time of physical and social loss and change from midlife onward [21]. However, other studies of older adults across two countries have yielded evidence to the contrary $[14,36]$. Attitudes toward health have also significantly differed between older people residing in eight different European countries [37]. Hence, we asked: would older adults' attitudes toward their own aging mediate the effect of their health satisfaction ratings upon their QOL in a different way when we account for which country they are from?

Age and gender have been found to consistently influence beliefs about the aging self in terms of age-related morale [11], aging in general [14], personal development [30], and physical and social loss [17]. Women appear to be at a disadvantage as they age, particularly when it comes to expectations of physical, mental and social decline $[18,23]$. Both age and gender have been found to also significantly shaped attitudes toward the physical changes of aging in Brazil, but when looking across cultures, age hardly influenced attitudes toward physical change and women were more positive about psychological growth [38]. The effect of gender on perceptions of bodily aging is less clear [14,36,39]. Subjective health appraisals can also be affected by age $[13,26]$ and gender $[13,28,40]$. Hence, we also asked: would older adults' attitudes toward their own aging mediate the effect of their health satisfaction ratings upon their QOL in a different way when we account for how old they are or whether they are a man versus a woman?

In summary, there has been little research relating to the linkages between attitudes to aging, health, and QOL. The findings from our literature review suggest that subjective ratings of health have explained selfappraisals of older age, and in two studies of older people, self-appraisals of older age have either been associated with or found to explain QOL. There is less literature regarding the influence of the older person's country of origin, age, or gender. Hence we: (a) tested our hypothesis that older adults' attitudes toward their own aging would partly mediate the effect of their health satisfaction ratings upon their global, physical, psychological, social, and environmental quality of life; and (b) explored whether these attitudes would mediate the relationship between health satisfaction and QOL in the same way when we account for older adults' country of origin, and their age and gender. Understanding these relationships may help practitioners and policy makers consider strategies to enhance QOL.

\section{Methods}

\section{Sample and procedure}

We conducted a secondary analysis of data from the WHOQOL-OLD field study [41]. The purpose of the original study was to develop and test a new measure of QOL for older adults. Data were collected in 2003 simultaneously in 20 countries. These centres were: Melbourne, Australia; Paris, France; Geneva, Switzerland; Bath, England; Edinburgh, Scotland; Seattle, USA; Beer Sheeva, Israel; Barcelona, Spain; Tokyo, Japan; Izmir, Turkey; Vilnius, Lithuania, Prague, Czech Republic; Budapest, Hungary; Victoria, Canada; Oslo, Norway; Umea, Sweden; Copenhagen, Denmark; Leipzig, Germany; Porto Alegre, Brazil; Montevideo, Uruguay. Each centre in the WHOQOL-OLD field study received ethical approval and adhered to relevant local ethical standards. Data were collected on 5566 older people, primarily in community settings using a variety of culturally appropriate methods.

Each centre in the WHOQOL-OLD field study obtained their own IRB approval. This analysis is consistent with the original purpose of the WHOQOL-OLD field study.

\section{Measures}

Participants' perspectives of their own aging process were measured using the Attitudes to Aging Questionnaire or AAQ [42]. The AAQ contains 24 items representing three subscales: psychosocial loss, psychological growth, and physical change. The eight items in each subscale are measured on a 5-point Likert scale. Scores on the subscales range from 8 to 40. Item-response categories range from strongly disagree to strongly agree. On the AAQ, the higher a score is, the more positive the attitude towards one's own aging process in that area. The subscale structure of the AAQ has been established in 15 countries using classical and modern psychometric methods [21,26,42]. The internal consistency reliability in this study was .86 for the whole instrument, and .81 for physical change, .74 and .81 for psychological growth and loss, respectively.

The WHOQOL-BREF is a short version of the WHOQOL-100 designed to measure generic QOL across cultures [43]. It has been translated into 50 languages. The scale contains four domains: physical (7 items), psychological (6 items), social relationships (3 items) and environmental (8 items). Each item is scored on a 5-point Likert scale in relation to the last two weeks, and higher scores indicate higher QOL. Cronbach's alpha coefficient values for the WHOQOL-BREF physical, psychological, social and environmental domains were 0.86, 0.79, 0.63, and .83 respectively. We also calculated the BREF score as the sum of the BREF domains [44]. For subjective health, we used the BREF item "how satisfied are you with your health?" with five response categories ranging from "Very dissatisfied" to "Very satisfied". 


\section{Data analysis}

We conducted multilevel regression analyses to predict the WHOQOL-BREF scale scores using satisfaction with health, the three AAQ subscales and age and gender as independent variables and country as a random effect. All study variables had fewer than 3\% missing values, and data were deleted list-wise prior to our analyses. We had complete data for analysis on 4593 participants.

First, we examined whether the intercept in the regression equation varied by country of origin, and then we tested whether the slopes of the independent variables differed across the 20 country samples. We used the Mixed Model module of SPSS for multilevel models [45] to examine these models. In accordance with the findings of the multilevel regression analysis, we subjected the correlation matrix of study variables to a path analysis to determine if the three AAQ subscales acted as mediators between health satisfaction and QOL. For path models, we used Mplus software [46] and for explicit statistical tests for multiple mediators, SPSS [47].

\section{Results}

\section{Participant characteristics}

In Table 1, descriptive statistics for the model variables for each country of origin sample are presented. Across all 20 country samples, the mean age was 72.10 (se = 7.92 years) and $42.8 \%$ were female. Just under one-third of all participants $(26.9 \% ; \mathrm{n}=1235)$ had primary schooling, $18.8 \%(\mathrm{n}=863)$ completed high school, and $43.3 \%$ $(n=1988)$ reported some form of post-secondary education. Slightly more than half were married/partnered (56.2\%; $\mathrm{n}=2581)$; otherwise, $5.7 \%(\mathrm{n}=261)$ were single, $7.1 \%(n=326)$ separated or divorced, and $29.7 \%(n=1364)$ widowed. Slightly more than half $(59.3 \%$; $n=2723)$ reported having, on average, one or more chronic illnesses, and a large proportion lived in their own home either assisted by others $(41.3 \%$; $n=1896)$ or unsupported $(38.2 \% ; n=1754)$. Few lived in residential care and nursing homes $(6.9 \% ; n=316)$. Nearly two-thirds $(n=3063)$ were retired; $9.1 \%(n=418)$ engaged in paid work and 2425 (52.8\%) volunteered.

\section{Multilevel regression analysis}

In the multilevel regression analysis of the WHOQOLBREF scale (Table 2), it was found that while allowing the intercept to vary across each country (a random intercept model) was a clear improvement over a model with a single fixed intercept, there was no improvement in the model when we allowed the slopes of the independent variables to also vary (a random slope and intercept model). This allowed us to form a partial correlation matrix among the QOL, attitudes toward aging, and satisfaction with health variables that removed the effects of the older person's country of origin, and age and sex.

\section{Partial correlation matrix and path analysis}

Table 3 presents the partial correlation matrix ${ }^{a}$. Health satisfaction was significantly correlated with all three Attitudes to Aging subscales, and the global score on the WHOQOL-BREF. Correlations between the overall score of the WHOQOL-BREF and the attitudes to aging subscales were strongest for physical change and weakest for psychological growth. Figure 1 shows the standardized parameter estimates for the path model of this matrix [48]. The standard errors for the estimated beta weights were all statistically significant $(\mathrm{p}<0.01)$ and ranged from se $=0.007$ to $\mathrm{se}=0.012$.

Testing for mediation involves estimating whether the path coefficient between health satisfaction and each mediator multiplied by the path coefficient between each mediator and the global BREF score is significantly different from 0 . Bootstrap resampling was employed to estimate the confidence interval on the path products for each of the multiple mediators simultaneously [45,47]. The total mediation effect and each of the mediations through the Attitudes to Aging subscales proved to be statistically significant (all $\mathrm{p}$ values $<0.01$ ). As can be seen in Figure 1, while health satisfaction directly affected QOL (beta $=.38$, $\mathrm{p}<.01$ ), its effect on QOL was also partly mediated by all three Attitudes to Aging subscales. Path products for these mediations were highest for physical change (beta $=.122, \mathrm{p}<.01)$ and psychosocial loss (beta $=.102$, $\mathrm{p}<.01$ ) compared to psychological growth (beta $=.024$, $\mathrm{p}<.01)$. The total effect of health satisfaction on QOL (which is identically the beta coefficient of health satisfaction in a model where the AAQ subscales are not included) was strong (beta $=.628, \mathrm{p}<.01$ ).

Table 4 shows the parameter estimates for our model with the four specific domains of the BREF as dependent variables. Excepting the non-significant path from growth to environmental QOL, the level of significance and the direction of path relationships were identical to our global QOL model. While there are differences in path coefficients from attitudes to aging and each of the BREF domains compared to the model using global QOL, the means of the four domain-specific path coefficients for loss, change, and growth to each BREF domain were similar to their global QOL counterparts, partly due to the appreciable correlations among the BREF domains. These correlations ranged from .369 to .619 ( $\mathrm{p}<.001)$.

\section{Discussion}

In this cross-sectional study of 4593 older people, attitudes toward physical change, psychosocial loss, and psychological growth partly mediated the impact of health satisfaction on QOL, and did so in the same way across all 20 country samples and among men and women at any age. This pattern of findings suggests that QOL judgments were significantly affected by participants' satisfaction with 
Table 1 Study variable descriptive statistics across 20 country samples

\begin{tabular}{|c|c|c|c|c|c|c|c|c|}
\hline Country & $\begin{array}{c}\text { Gender } \\
\text { Male }\end{array}$ & $\begin{array}{c}\text { Age } \\
M \\
(S E)\end{array}$ & $\begin{array}{c}\text { Satisfaction with health } \\
\qquad M \\
\text { (SE) }\end{array}$ & $\begin{array}{c}\text { Psychosocial loss } \\
M \\
\text { (SE) }\end{array}$ & $\begin{array}{c}\text { Physical change } \\
M \\
\text { (SE) }\end{array}$ & $\begin{array}{c}\text { Psychosocial growth } \\
M \\
\text { (SE) }\end{array}$ & $\begin{array}{c}\text { BREF } \\
M \\
(S E)\end{array}$ & $N$ \\
\hline \multirow[t]{2}{*}{ Edinburgh } & $34 \%$ & 77.35 & 3.7 & 30.39 & 25.23 & 26.34 & 277.85 & 97 \\
\hline & & $(1.07)$ & $(.11)$ & $(.51)$ & $(.53)$ & $(.50)$ & $(5.51)$ & \\
\hline \multirow[t]{2}{*}{ Bath } & $38.2 \%$ & 69.16 & 3.8 & 32.12 & 27.82 & 25.84 & 286.99 & 128 \\
\hline & & $(.61)$ & $(.08)$ & (.41) & $(.47)$ & $(.45)$ & $(3.98)$ & \\
\hline \multirow[t]{2}{*}{ Leipzig } & $54.8 \%$ & 72.32 & 3.3 & 29.16 & 27.99 & 25.3 & 278.09 & 310 \\
\hline & & $(.49)$ & $(.05)$ & $(.31)$ & (.30) & $(.23)$ & $(2.84)$ & \\
\hline \multirow[t]{2}{*}{ Barcelona } & $44.5 \%$ & 71.6 & 3.1 & 26.9 & 26.44 & 27.5 & 240.48 & 218 \\
\hline & & (.49) & $(.06)$ & $(.34)$ & $(.33)$ & $(.29)$ & $(3.62)$ & \\
\hline \multirow[t]{2}{*}{ Copenhagen } & $49.7 \%$ & 71.19 & 3.8 & 30.15 & 28.79 & 27.95 & 297.66 & 298 \\
\hline & & $(.47)$ & $(.05)$ & $(.29)$ & $(.32)$ & $(.27)$ & $(2.74)$ & \\
\hline \multirow[t]{2}{*}{ Paris } & $50 \%$ & 78.3 & 2.8 & 25.08 & 21.41 & 22.69 & 235.93 & 86 \\
\hline & & $(.79)$ & (.10) & $(.67)$ & $(.60)$ & $(.55)$ & $(5.32)$ & \\
\hline \multirow[t]{2}{*}{ Prague } & $40.4 \%$ & 71.18 & 3.1 & 25.73 & 23.89 & 26.16 & 245.91 & 309 \\
\hline & & $(.44)$ & $(.05)$ & (.33) & $(.31)$ & $(.23)$ & $(2.74)$ & \\
\hline \multirow[t]{2}{*}{ Budapest } & $34 \%$ & 73.47 & 3.1 & 26.4 & 24.3 & 26.29 & 239.43 & 279 \\
\hline & & $(.53)$ & $(.05)$ & $(.36)$ & $(.31)$ & $(.26)$ & (3.19) & \\
\hline \multirow[t]{2}{*}{ Oslo } & $48.4 \%$ & 74.22 & 3.7 & 29.91 & 27.15 & 28.24 & 280.84 & 254 \\
\hline & & $(.51)$ & $(.06)$ & $(.30)$ & $(.34)$ & $(.28)$ & $(2.81)$ & \\
\hline \multirow[t]{2}{*}{ Victoria } & $46.0 \%$ & 72.93 & 3.81 & 31.91 & 28.17 & 28.93 & 304.7 & 202 \\
\hline & & $(.60)$ & $(.07)$ & $(.36)$ & $(.41)$ & $(.31)$ & (3.73) & \\
\hline \multirow[t]{2}{*}{ Melbourne } & $41.7 \%$ & 75.62 & 3.6 & 30.46 & 26.5 & 28.33 & 280.29 & 331 \\
\hline & & (.39) & $(.06)$ & $(.31)$ & $(.29)$ & $(.22)$ & $(2.86)$ & \\
\hline \multirow[t]{2}{*}{ Seattle } & $42.5 \%$ & 71.69 & 3.6 & 31.68 & 27.21 & 29.76 & 298.97 & 268 \\
\hline & & $(.51)$ & $(.06)$ & $(.34)$ & $(.34)$ & $(.23)$ & $(3.27)$ & \\
\hline \multirow[t]{2}{*}{ Beer-Sheva } & $32.6 \%$ & 70.16 & 3.5 & 29.4 & 27.94 & 28.16 & 273.67 & 196 \\
\hline & & $(.54)$ & $(.07)$ & (.43) & $(.39)$ & $(.36)$ & (3.88) & \\
\hline \multirow[t]{2}{*}{ Tokyo } & $47.9 \%$ & 68.53 & 3.4 & 28.38 & 28.32 & 25.49 & 265.30 & 144 \\
\hline & & $(.50)$ & $(.08)$ & $(.45)$ & (.43) & $(.34)$ & $(4.23)$ & \\
\hline \multirow[t]{2}{*}{ Umea } & $48.6 \%$ & 72.15 & 3.6 & 29.55 & 26.82 & 28.23 & 275.26 & 393 \\
\hline & & $(.41)$ & $(.05)$ & $(.27)$ & $(.28)$ & $(.23)$ & $(2.33)$ & \\
\hline \multirow[t]{2}{*}{ Porto Alegre } & $32.6 \%$ & 71.69 & 3.7 & 30.07 & 28.3 & 30.46 & 283.09 & 319 \\
\hline & & $(.43)$ & $(.05)$ & (.32) & $(.26)$ & $(.20)$ & $(2.66)$ & \\
\hline \multirow[t]{2}{*}{ Montevideo } & $26.6 \%$ & 72.90 & 3.8 & 27.04 & 29.79 & 30.50 & 281.37 & 184 \\
\hline & & (.65) & $(.07)$ & (.48) & $(.34)$ & $(.28)$ & (3.8) & \\
\hline \multirow[t]{2}{*}{ Izmir } & $47.7 \%$ & 70.92 & 2.9 & 24.22 & 22.4 & 26.84 & 225.13 & 327 \\
\hline & & (.29) & $(.06)$ & (.33) & $(.33)$ & $(.24)$ & $(3.12)$ & \\
\hline \multirow[t]{2}{*}{ Geneva } & $46.7 \%$ & 73.84 & 3.7 & 30.93 & 27.20 & 24.35 & 292.67 & 122 \\
\hline & & $(.64)$ & $(.08)$ & (.49) & $(.32)$ & $(.47)$ & $(4.26)$ & \\
\hline \multirow[t]{2}{*}{ Vilnius } & $32.3 \%$ & 68.45 & 3.0 & 25.45 & 26.07 & 27.40 & 234.09 & 282 \\
\hline & & $(.38)$ & $(.05)$ & $(.34)$ & $(.31)$ & $(.23)$ & (2.9) & \\
\hline
\end{tabular}


Table 2 Multilevel model for global WHOQOL-BREF

\begin{tabular}{|c|c|c|c|}
\hline Model & Model parameter & $\begin{array}{c}\text { Parameter estimates } \\
(95 \% \mathrm{Cl})\end{array}$ & $\begin{array}{c}-2 \text { Log } \\
\text { likelihood }\end{array}$ \\
\hline \multirow{11}{*}{$\begin{array}{l}\text { Fixed slope, } \\
\text { random } \\
\text { Intercept }\end{array}$} & Fixed effects & & 43485 \\
\hline & Intercept & $28.4(14.4,42.4)^{* * *}$ & \\
\hline & Health satisfaction & $20.4(19.2,21.7)^{* * *}$ & \\
\hline & Physical change & $2.7(2.5,2.9)^{* * *}$ & \\
\hline & Psychosocial loss & $2.2(2.0,2.5)^{* * *}$ & \\
\hline & $\begin{array}{l}\text { Psychosocial } \\
\text { growth }\end{array}$ & $1.2(0.9,1.4)^{* * *}$ & \\
\hline & Age & $.03(-0.1,0.2)^{a}$ & \\
\hline & Sex & $-1.1(-3.1,0.9)^{\mathrm{a}}$ & \\
\hline & Variances & & \\
\hline & Residual & $1076.9(1032.8,1122.9)^{* * *}$ & \\
\hline & Intercept & $82.8(41.2,166.8)^{* *}$ & \\
\hline \multirow{7}{*}{$\begin{array}{l}\text { Random slope } \\
\text { \& intercept }\end{array}$} & Variances & & 43470 \\
\hline & Residual & $1065.2(1020.9,1111.4)^{* * *}$ & \\
\hline & Intercept & $44.2(3.6,549.6)^{a}$ & \\
\hline & Health satisfaction & $1.8(0.2,20.6)^{a}$ & \\
\hline & Physical change & $0.2(0.05,0.5)^{a}$ & \\
\hline & Psychosocial loss & $0.01(0.00,14.5)^{a}$ & \\
\hline & $\begin{array}{l}\text { Psychosocial } \\
\text { growth }\end{array}$ & $0.05(0.01,0.4)^{a}$ & \\
\hline
\end{tabular}

Age and sex slopes fixed to allow convergence in the random slope and intercept model. Fixed Effects are not shown as they differ only marginally from the fixed slope, random intercept model. $\mathrm{Cl}$ confidence interval. ${ }^{\mathrm{a}} \mathrm{NS},{ }^{* *} \mathrm{p}<.01,{ }^{* * *} \mathrm{p}<.001$.

health and attitudes to physical and psychosocial aspects of the aging self.

Participants who were dissatisfied with their health had more negative attitudes toward their own aging in terms of physical change. This finding is consistent with other studies of older people where it has been found that declining health can result in anticipation of future changes for the worse [19] and negative feelings regarding bodily aging [20]. Perceived health has also been most strongly associated with physical decline [18]. Being in good health in older age has been found to yield a sense of hope for maintaining health-related resources and physical well-being [17] rather than seeing oneself as getting old (in terms of physical health difficulties and concerns) [49], and change for the worse, including one's energy [13]. Further support for these findings is our observation that attitudes toward physical change had the largest effect upon on our participants' physical QOL in terms of their energy, sleep, mobility, and activities.

Participants' health satisfaction ratings also affected their attitudes towards psychosocial loss. Benefits of positive perceived health include less anticipation of losses in social relationships and loneliness [17], and greater social interaction and involvement with volunteer and organized groups [50]. Social participation offers the opportunity to strengthen peoples' sense of identity and belonging [51]. Thus, in terms of the AAQ subscales, the paths from psychosocial loss to psychological (positive feelings, thinking, esteem and body) and social (sex, support, and relationships) QOL in our study are consistent with other findings. The smaller correlations between loss and psychological and social QOL reported by others [26] do not account for the effects of satisfaction with health.

Health satisfaction had the weakest effect upon psychological growth, and this effect was negative. Nevertheless, this path coefficient from health satisfaction to psychological growth was significant across all 20 country samples. Perhaps lower health satisfaction is an impetus for older adults to explore opportunities for psychological growth. Poor health has been conceived of as a factor spurring on the search for meaning and purpose in life in older age [52]. Others argue that ill health is not synonymous with believing there is little left to achieve in older age [6]. Psychological growth had a modest effect on global QOL but its significance speaks to the importance of growthenhancing generative activities such as sharing past accomplishments, receiving recognition in life, and planning future activities to older peoples' overall QOL ratings [53].

Adaptation to physical and psychological change in later life can be expressed through being and doing in familiar environments, practicing familiar skills, and interacting with familiar social ties [54]. In this study, attitudes toward psychosocial loss and physical change had a similar significant impact on environmental QOL across all 20 country samples, and regardless of age or gender. Others have reported moderate correlations

Table 3 Relationships among health satisfaction, attitudes to aging scales, and WHOQOL-BREF

\begin{tabular}{|c|c|c|c|c|c|}
\hline & Satisfaction with health & Psychosocial loss & Physical change & Psychosocial growth & BREF \\
\hline Satisfaction with health & 1.000 & $.429^{* * *}$ & $.545^{* * *}$ & $.274^{* * *}$ & $.669^{* * *}$ \\
\hline Psychosocial loss & $.350^{* * *}$ & 1.000 & $.365^{* * *}$ & $.210^{* * *}$ & $.599^{* * *}$ \\
\hline Physical change & $.515^{* * *}$ & $.303^{* * *}$ & 1.000 & $.481^{* * *}$ & $.607^{* * *}$ \\
\hline Psychological growth & $.236^{* * *}$ & $.187^{* * *}$ & $.482^{* * *}$ & 1.000 & $.369^{* * *}$ \\
\hline BREF & $.632^{* * *}$ & $.518^{* * *}$ & $.575^{* * *}$ & $.363^{* * *}$ & 1.000 \\
\hline
\end{tabular}

Age, sex, and country partialled (below diagonal) and correlations (above diagonal). $\mathrm{df}=4570$. ${ }^{* * *} \mathrm{p}<.001$. 


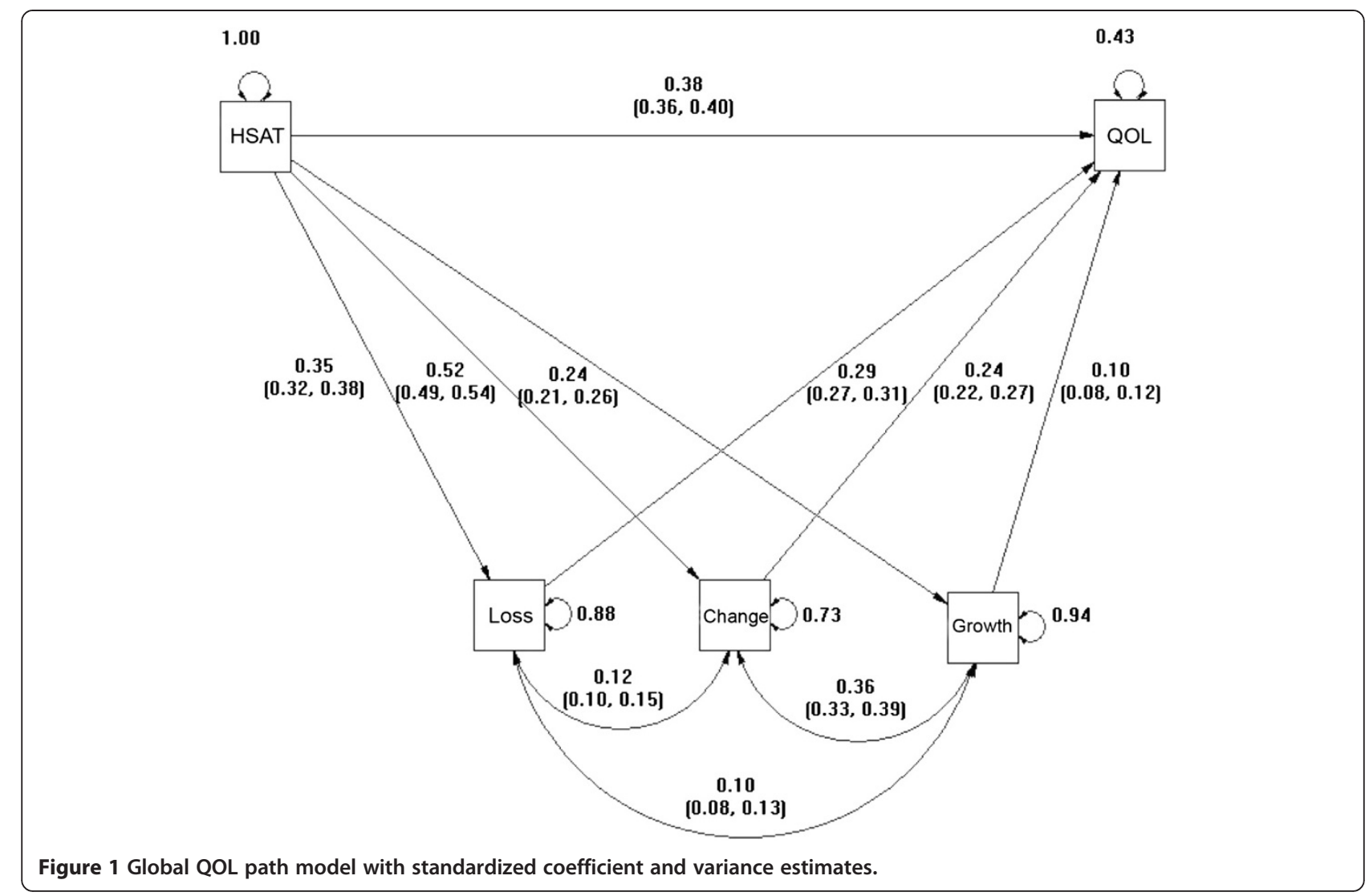

between attitudes toward loss and change in older age and environmental QOL across two countries but did not account for age or gender [26]. Accessible and quality environments provide opportunities for social interaction and support the realization of personal goals and projects [55]. Supportive environments have also enhanced older peoples' sense of membership to a community [56] and place belonging [57]. Perhaps older peoples' attitudes about psychosocial loss and physical change are an extension of environmental resources, incentives and constraints that facilitate adjustment and accomplishment in later life [58].

Of particular interest to us was that physical change had an impact upon social QOL that was two-thirds smaller than that of psychosocial loss. Far larger path coefficients have been reported over time between positive age-related morale, including physical energy, and perceived levels of social support among women with multiple sclerosis at a wide variety of ages [59]. Lesser age-related expectancies of physical decline among older Korean men and women have also been strongly associated, in part, with taking more responsibility for interpersonal relationships [60]. Others believe the importance of physical appearance in older age is rooted in a social standard of aging that is more forgiving of men and orientates women toward a youthful appearance [61]. However, women are not necessarily more negative toward physical signs of aging $[14,36,39]$. In our study, physical change appeared to be of equal social significance to men and women, and appeared to have a small impact on the quality of their personal and sexual relationships and anticipations of social support. Perhaps in our case,

Table 4 Parameter estimates for mediation models for WHOQOL-BREF Domains

\begin{tabular}{lcccc}
\hline Model path & $\begin{array}{c}\text { Physical } \\
\text { Parameter }(\mathbf{9 5 \%} \text { Cl) }\end{array}$ & $\begin{array}{c}\text { Psychological } \\
\text { Parameter }(\mathbf{9 5 \%} \mathrm{Cl})\end{array}$ & $\begin{array}{c}\text { Social relationships } \\
\text { Parameter }(\mathbf{9 5 \%} \mathrm{Cl})\end{array}$ & $\begin{array}{c}\text { Environment } \\
\text { Parameter (95\% Cl) }\end{array}$ \\
\hline Health satisfaction- > QOL & $0.48(0.45,0.50)^{* *}$ & $0.28(0.26,0.31)^{* *}$ & $0.21(0.18,0.24)^{* *}$ & $0.24(0.21,0.27)^{* *}$ \\
Psychosocial loss - > QOL & $0.22(0.20,0.24)^{* *}$ & $0.34(0.32,0.36)^{* *}$ & $0.26(0.23,0.29)^{* *}$ & $0.28(0.25,0.30)^{* *}$ \\
Physical change - > QOL & $0.31(0.29,0.33)^{* *}$ & $0.18(0.15,0.20)^{* *}$ & $0.08(0.05,0.12)^{* *}$ & $0.22(0.19,0.25)^{* *}$ \\
Psychosocial growth - > QOL & $-0.07(-0.05,-0.09)^{* *}$ & $0.18(0.15,0.20)^{* *}$ & $0.15(0.13,0.18)^{* *}$ & $0.03(-0.01,0.05)^{a}$ \\
\hline
\end{tabular}

Remaining parameters to those presented in Figure 1. QOL quality of life, Cl confidence interval. ${ }^{a} \mathrm{NS} .{ }^{* *} \mathrm{p}<.01$ 
this small impact may be partly owing to older adults selectively investing their time and energy with people when they feel a more meaningful or closer connection [62]. Perhaps the personal relationships our participants continued to invest offered them unconditional physical regard. Relationships of older adults with people with whom they have affectionate ties have tended to depend less on what older people can do in terms of their physical performance; thus, even when physical declines are considerable, older people can still find intimacy in close relationships [63]. Late-life friendships, akin to sibling ties, are often characterized by a similar status in terms of age and social class, long-term reciprocity, and a shared history fostering self-continuity [64]. Similarly aged peers could also have intimate knowledge of what it is like to be living with the physical changes of aging [42].

The limitations of this study relate to a nonrepresentative sample and use of an existing data set. Convenience samples were used to collect data in many of the countries, thus, our study sample is not likely to be representative of older people in the 20 countries. The sample is skewed to a healthier younger old population, given the mean age of 72 years of our respondents and that they were satisfied with their health. Hence, our findings may not apply to frail or older-old populations. Further, data were not available from all regions of the world. These limitations preclude generalization to other samples. The cross-sectional nature of our data prevented us from ascertaining causal relationships. The low reliability of the social domain of the WHOQOL-BREF is an added concern, and similar reliability scores have been noted in other studies $[24,65]$. Future research could explore the effect of socioeconomic status on these variables, since it has previously been found to influence attitudes to aging $[11,15,28]$, QOL $[66,67]$, and self-rated health [13]. For this study, a suitable measure of socioeconomic status was not available.

\section{Conclusions}

In this study, older peoples' attitudes toward their own aging with respect to physical change, psychosocial loss, and psychological growth partly mediated the relationship between their health satisfaction and QOL. These partly mediated effects manifested in the same way across 20 country samples, regardless of the age or gender of our 4593 participants. Participants' attitudes toward physical change were the strongest mediator of health satisfaction upon global and domain-specific quality of life, followed by psychosocial loss and psychosocial growth. The direction of these partly mediated effects indicated that participants who were dissatisfied with their health harboured more negative attitudes toward physical change and psychosocial loss. In contrast, health dissatisfaction appeared to serve as an impetus for psychological growth. The subsequent effects of participants' attitudes upon QOL, in some instances, were marginal; physical change in relation to social QOL serves as a case in point. Nonetheless all three attitudes were found to significantly impact participant QOL, both globally and across four life domains.

Our study is the first cross-cultural study with a large sample to show that QOL judgements between 60 to 100 years of age are a product of men's and women's perceptions of health-related circumstances, and attitudes toward physical and psychosocial aspects of the aging self. The findings of this study make a significant contribution to the QOL literature by shedding some light on the linkages between attitudes to aging, health, and QOL in older age, particularly across cultures. With ever-increasing life expectancy globally, factors affecting older peoples' capacity to live a longer life of quality is a pressing issue. More research is essential. A prospective study that involves longitudinal data would certainly enhance our ability to make causal inferences. In this prospective study we would use multiple measures of subjective health to determine whether the relationship between health satisfaction and psychological growth can be replicated beyond this studied sample. Further research regarding the specific roles that friends versus family or intimate ties play in helping older people navigate the physical changes of aging and the effects of socioeconomic status would be important. To our knowledge, interventions for enhancing how older people view aging in relation to QOL have yet to be identified. Nevertheless, exploring how psychosocial interventions such as counselling, support groups, and socialization activities might affect perceived health and attitudes to aging could be valuable since these factors have a significant influence on QOL of older adults.

\section{Endnote}

${ }^{\text {a}}$ The partial correlation matrix for WHOQOL-BREF domains is available from GL upon request.

\section{Abbreviations}

QOL: Quality of life; Se: Standard error; Cl: Confidence interval; HSAT: Health satisfaction.

\section{Competing interests}

Neither the primary author nor the co-authors have any competing interests to report. This manuscript has been submitted for review to Health and Quality of Life Outcomes alone.

\section{Authors' contributions}

All authors contributed to the conception and design of the paper. AM was the primary investigator for Canada in the WHOQOL-OLD field study. DS conducted all data analyses. GL developed a draft of the manuscript. All authors took part in interpreting the data and making critical revisions. All authors read and approved the final manuscript. 


\section{Acknowledgements}

The authors also gratefully acknowledge the contributions of the WHOQOLOLD Group, who collected the data used in this study. The WHOQOL-OLD group is composed of: Prof. M. Power, K. Quinn (University of Edinburgh, UK); Dr. R. Lucas (Institut Català de I'Envelliement, Barcelona, Spain); Prof. S. Skevington (University of Bath, UK); Prof. M. Amir*, Dr. Y. B. Ya'acov, T. NarkissGuez (Ben Gurion University of the Negev, Beer-Sheva, Israel); Prof. L. Kullman (National Institute for Medical Rehabilitation, Budapest, Hungary); G. BechAnderson (Fredriksborg General Hospital, Copenhagen, Denmark); Prof. JiQian Fang (Sun Yat-Sen University of Medical Science, Guangzhou, China); Prof. G. Hawthorne (University of Melbourne, Australia); Prof. M.C. Angermeyer, Dr. H. Matschinger, I. Winkler (University of Leipzig, Germany); Dr. M. Kalfoss (Diakonova University College, Oslo, Norway); Dr. E. Dragomirecka (Prague Psychiatric Centre, Czech Republic); Dr. M. Tazaki (University of Tokyo, Japan); Prof. M. Eisemann (Tromsø University, Norway), B. Nygren (Umea University, Sweden); Prof. A. Molzahn (University of Alberta, Canada); Dr. J. Ceremnych (Scientific Department of Gerontology, Vilnius, Lithuania); Dr. R. Krech (WHO Europe, Copenhagen, Denmark); Dr. M. Fleck (University of the State of Rio Grande do Sul, Brazil); Prof. E. Eser (Celal Bayar University, Turkey); Prof. N. v. Steinbüchel (University of Genf, Switzerland); Dr. A. LePlege (INSERM, Paris, France); Dr. D. Bushnell (University of Washington, Seattle, USA); Dr. A. Chan (Queen Elisabeth Hospital Kowloon, Hong Kong); Dr. L. Schwartzmann (Department of Medical Psychology, Montevideo, Uruguay), Dr. R. Kilian (University of Ulm, Germany). ${ }^{*}$ We note with great sadness the death of Dr. Marianne Amir in January 2004.

\section{Funding}

The design, execution, and analysis in the international WHOQOL OLD Group Field studies were supported by the European Commission Fifth Framework [QLRT-200-00320] and the University of Victoria internal Social Sciences and Humanities Research Council of Canada grants program.

\section{Author details}

${ }^{1}$ Faculty of Nursing, University of Alberta, 11405-87 Avenue, Edmonton, AB T6G 1C9, Canada. 'Faculty of Nursing, University of Alberta, Edmonton, $A B$, Canada. ${ }^{3} \mathrm{~S} c h o o l$ of Public Health and Faculty of Nursing, University of Alberta, Edmonton AB, Canada.

Received: 5 June 2013 Accepted: 20 August 2013

Published: 28 August 2013

\section{References}

1. Erikson EH, Erikson JM, Kivnick HQ: Vital involvement in old age. New York: Norton; 1986

2. Reed PJ: Self-transcendence and mental health in the oldest-old. Nurs Res 1991, 40:5-11.

3. Walker CA: Change readiness: a construct to explain health and life transitions. J of Theory Constr Test 2004, 8:26-33.

4. Halvorsrud L, Kalfoss M: The conceptualization and measurement of quality of life in older adults: a review of empirical studies published during 1994-2006. Eur J Ageing 2007, 4:229-246.

5. Grundy E: Aging and vulnerable elderly people: European perspectives. Ageing Soc 2006, 26:105-134.

6. Higgs $P$, Hyde M, Wiggins R, Blane D: Researching quality of life in early old age: the importance of the sociological dimension. Soc Policy Adm 2003, 37:239-252.

7. Prislin R, Crano WD: Attitude and attitude change: the fourth peak. In Attitudes and attitude change. Edited by Crano WD, Prislin R. New York: Psychology Press; 2008:3-18.

8. Albarracin D, Wang W, Li H, Noguchi K: Structure of attitudes: judgements, memory, and implications for change. In Attitudes and attitude change. Edited by Crano WD, Prislin R. New York: Psychology Press; 2008:19-40.

9. Olson MA, Kendrick RV: Origins of attitudes. In Attitudes and attitude change. Edited by Crano WD, Prislin R. New York: Psychology Press; 2008:111-130.

10. De Garcio-Blanco M, Olmo JG, Arbones MM, Bosch PM: Analysis of self-concept in older adults in different contexts: validation of the subjective aging perception scale. Eur J Psychol Assess 2004, 20:262-274

11. Levy BR, Myers LM: Relationship between respiratory mortality and self-perceptions of aging. Psychol Health 2005, 20:553-564.
12. Levy BR, Slade MD, Kunkel SR, Kasl SV: Longevity increased by positive perceptions of aging. J Pers Soc Psychol 2002, 83:261-270.

13. Levy BR, Slade MD, Kasl SV: Longitudinal benefit of positive perceptions of aging on functional health. J Geront Ser B Psychol Soc Sci 2002, 57B:409-417.

14. Ron P: Elderly peoples' attitudes and perceptions of aging and old age: the role of cognitive dissonance. Int J Ger Psychiatr 2007, 22:656-662.

15. Demakakos P, Gjonca E, Nazroo J: Age identity, age perceptions, and health: evidence from the English longitudinal study of aging. Ann New York Acad Sci 2007, 1114:279-287.

16. Schafer MH, Shippee TP: Age identity, gender, and perceptions of decline: does feeling older lead to pessimistic dispositions about cognitive aging? J Geront Ser B Psychol Soc Sci 2010, 65:91-96.

17. Timmer E, Steverink N, Dittmann-Kohli F: Cognitive representations of future gains, maintenance, and losses in the second half of life. Int $J$ Aging Hum Dev 2002, 55(4):321-339.

18. Steverink N, Westerhof GJ, Bode C, Dittmann-Kohli F: The personal experience of aging, individual resources, and subjective well-being. J Gerontol Ser B Psychol Soc Sci 2001, 56B:364-373.

19. Furstenberg AL: Trajectories of aging: imagined pathways in later life. Int J Aging Hum Dev 2002, 55:1-24.

20. Wilcox S: Age and gender in relation to body attitudes: is there a double standard of aging? Psychol Women Q 1997, 21:549-565.

21. Chachomovic E, Fleck MP, Trentini CM, Laidlaw K, Power MJ: Development and validation of the Brazilian version of the Attitudes to Aging Questionnaire (AAQ): an example of merging classical psychometric theory and the Rasch measurement model. Health Qual Life Out 2008, 6(Special section):1. http://dx.doi.org/10.1186/1477-7525-6-5.

22. Westerhof GJ, Barrett AE: Age identity and subjective well-being: a comparison of the United States and Germany. J Gerontol Ser B Psychol Soc SCi 2005, 60B:S129-S136.

23. Sarkisan CA, Steers N, Hays RD, Mangione CM: Development of the 12item expectations regarding aging survey. Gerontologist 2005, 45:240-248.

24. Kalfoss M, Low G, Molzahn A: Suitability of the WHOQOL-BREF among older Canadians and Norwegians. Eur J Ageing 2008, 5:77-89.

25. Leventhal H, Colman S: Quality of life: a process review. Psychol Health 1997, 12:753-767.

26. Kalfoss M, Low G, Molzahn A: Reliability and validity of the attitudes to aging questionnaire for Canadian and Norwegian older adults. Scand J Car Sci 2010, 24(Suppl):75-85.

27. Mock SE, Eibach RP: Aging attitudes moderate the effect of subjective age on psychological well-being: evidence from a 10-year longitudinal study. Psychol Aging 2011, 26:979-986

28. Barrett AE: Socioeconomic status and age identity: the role of dimensions of health in subjective construction of age. J Gerontol Ser B Psychol Soc Sci 2003, 58B:S101-S109.

29. Jang Y, Poon LW, Kim SY, Shin BK: Self-perceptions of aging and health among older adults in Korea. J Aging Studies 2004, 18:485-496.

30. Wurm S, Tesch-Romer C, Tomasik MJ: Serious health events and thei impact on changes in subjective health and life satisfaction: the role of age and a positive view of aging. Eur J Ageing 2008, 5:117-127.

31. Moor C, Zimprich D, Schmitt M, Kliegel M: Personality, aging selfperceptions, and subjective health: a mediation model. Int J Aging Hum Dev 2006, 63:241-257.

32. Trigg $R$, Watts $S$, Jones $R$, Tod A, Elliman R: Self-reported quality of life ratings of people with dementia: the role of attitudes to aging. Psychogeriatrics 2012, 24:1085-1093.

33. Skevington SM, Lofty M, O'Connell KA: The World Health Organization's WHOQOL-BREF quality of life assessment: psychometric properties and results of the international field trial. A report from WHOQOL Group. Qual Life Res 2004, 13:299-310.

34. Smith JR, Hogg MA: Social identity and attitudes. In Attitudes and attitude change. Edited by Prislin R, Crano WD. New York: Psychology Press; 2008:337-360.

35. McConatha JT, Hayta V, Rieser-Danner L, McConatha D, Polat TS: Turkish and US attitudes to aging. Educ Gerontol 2004, 30:169-183.

36. Oberg P, Tornstram L: Attitudes toward embodied old age among Swedes. Int J Aging Hum Dev 2003, 56:133-153.

37. Kozlowska K, Szczecinska A, Roszkowski W, Brzozowska A, Alfonso C, Fjellstrom C, Morais C, Nielsen NA, Pfau C, Saba A, Sidenvall B, Turrini A, Raats M, Lumbers M: Patterns of healthy lifestyle and positive health attitudes in older Europeans. J Nutr Health Aging 2008, 12:728-733. 
38. Chachomovic E, Fleck M, Laidlaw K, Power MJ: Impact of major depression and subsyndromal symptoms on quality of life and attitudes to aging in an international sample of older adults. Gerontologist 2008, 48:593-602.

39. Baker L, Gringart E: Body image and self-esteem in older adulthood. Ageing Soc 2009, 29:977-995.

40. Choi NG: Determinants of self-perceived changes in health status among pre- and early-retirement populations. Int J Aging Hum Dev 2003, 56:197-222.

41. Power M, Quinn K, Schmidt S, the WHOQOL-OLD Group: Development of the WHOQOL-Old module. Qual Life Res 2005, 14:2197-2214.

42. Laidlaw K, Power MJ, Schmidt S, the WHOQOL-OLD Group: The attitudes to aging questionnaire (AAQ): development and psychometric properties. Int J Ger Psychiatr 2006, 22:367-379.

43. World Health Organization Quality of Life Group: The World Health Organization Quality of Life Assessment (WHOQOL): development and general psychometric properties. Soc Sci Med 1998, 46:1569-1585.

44. World Health Organization Quality of Life Group (1998b): Development of the World Health Organization WHOQOL-BREF Quality of Life Assessment. Psychol Med 1998, 28:551-558.

45. Heck RH, Thomas RL, Tabata LN: Multilevel and longitudinal modeling with IBM SPSS. New York: Routledge; 2010.

46. Muthén LK, Muthén BO: In Mplus user's guide. 5th edition. Edited by Muthén LK, Muthén BO. Los Angeles: Muthén and Muthén. 1998-2007.

47. Preacher KJ, Hayes AF: Asymptotic and resampling strategies for assessing and comparing indirect effects in multiple mediator models. Behav Res Methods 2008, 40:879-891.

48. McArdle JJ: The development of the RAM Rules for latent variable structural equation modelling. In Contemporary psychometrics. Edited by Maydeu-Olivares A, McArdle JJ. New Jersey: Lawrence Erlbaum Associates; 2005:274-275.

49. Keller MY, Leventhal EA, Larson B: Aging: the lived experience. Int J Aging Hum Dev 1989, 29:67-82.

50. Cornwell B, Laumann EO, Schumm LP: The social connectedness of older adults: a national profile. Am Sociolog Rev 2008, 73:185-203.

51. Reimer B, Lyons T, Ferguson N, Polanco G: Social capital as social relations: the contribution of normative structures. Sociolog Rev 2008, 56:256-274.

52. Fife B: The conceptualization of meaning in illness. Soc Sci Med 1994, 38:309-316

53. Low G, Molzahn A, Kalfoss M: Quality of life of older adults in Canada and Norway: examining the lowa model. West J Nurs Res 2008, 30:458-476.

54. Atchley R: A continuity theory of normal aging. Gerontologist 1989 , 29:183-190.

55. Horelli L: Environmental human-friendliness as a contextual determinant for quality of life. Eur Rev Appl Psychol 2006, 56:15-22.

56. Moser G: Quality of life and sustainability: toward person-environment congruity. J Environ Psychol 2009, 29:351-357.

57. Ng SH, Kam PK, Pong RWM: People living in aging buildings: their quality of life and sense of belonging. J Environ Psychol 2005, 25:347-360.

58. Anderson JE: Environment and meaningful activity. In Process of aging: social and psychological perspectives. Edited by Williams R, Tibbits C, Donahue W. New Jersey: Aldine Transaction; 1963:223-245.

59. Harrison T, Blozis S, Stuifbergen A: Longitudinal predictors of attitudes to aging among women with multiple sclerosis. Psychol Aging 2008, 23:823-832.

60. Kim SH: Older peoples' expectations regarding aging, health-promoting behaviour and health status. J Adv Nurs 2008, 65:84-91.

61. McConatha JT, Schnell F, Volkwein K, Riley L, Leach E: Attitudes toward aging: a comparative analysis of young adults from the United States and Germany. Int J Aging Hum Dev 2003, 57:203-215.

62. Carstensen LL, Fung HH, Charles ST: Socioemotional selectivity theory and the regulation of emotion in the second half of life. Motiv Emotion 2003, 27:103-123.

63. Steverink N, Lindenberg S: Which social needs are important for subjective well-being? What happens to them with aging? Psychol Aging 2006, 21:281-290.

64. McRae H: Strong and enduring ties: older women and their friends. Can J Aging 1996, 15:374-392.

65. Jaracz K, Kalfoss MH, Gorna K, Baczyna G: Quality of life in Polish respondents: psychometric properties of the Polish WHOQOL-Bref. Scan J Car Sci 2006, 20:251-260.
66. Puts MTE, Shekary N, Widdershoven G, Helde J, Lips P, Deeg DJH: What does quality of life mean to older frail and non-frail community-dwelling adults in the Netherlands? Qual Life Res 2007, 16:263-277

67. Wilhelmson K, Andersson C, Waern M, Allebeck P: Elderly people's perspectives on quality of life. Ageing Soc 2005, 25:585-600.

doi:10.1186/1477-7525-11-146

Cite this article as: Low et al:: Attitudes to aging mediate the relationship between older peoples' subjective health and quality of life in 20 countries. Health and Quality of Life Outcomes 2013 11:146.

\section{Submit your next manuscript to BioMed Central and take full advantage of:}

- Convenient online submission

- Thorough peer review

- No space constraints or color figure charges

- Immediate publication on acceptance

- Inclusion in PubMed, CAS, Scopus and Google Scholar

- Research which is freely available for redistribution

Submit your manuscript at www.biomedcentral.com/submit
C Biomed Central 